\title{
PERCEPTION OF STIGMA AMONG CAREGIVERS OF MENTALLY ILL PEOPLE
}

\author{
Pandey S
}

Department of Nursing, Nepal Medical College Teaching Hospital, Attarkhel, Gokarneshwor-8, Kathmandu, Nepal

\begin{abstract}
The lives of people with mental illness are altered by the symptoms of the illness, attitudes of people that view symptoms as threatening and uncomfortable, which foster stigma and discrimination within social circles. The catch of the study was to assess the stigmatizing beliefs among Caregivers of persons with mental illness. A descriptive and exploratory study was conducted with purposive sampling technique among 50 caregivers with interview method of mental illness patient with purposive sampling technique at Nepal Medical College teaching Hospital, Jorpati, Kathmandu, Nepal in Oct 2017- Nov 2017. The study revealed that the most of caregivers (62\%) feel burdened financially, and about $64 \%$ think that people with mental illness are dangerous. Most of the care givers(70\%) think that the mentally ill people are violent. More than half (54\%) of the caregivers think voluntary organizations are not doing adequate work in the field of mental health and $72 \%$ feel health organizations are giving less priority to mental illness as compared to other disorder. Most of the caregivers (66\%) think that their occupational life has been interfered by the family member's illness, and 56\% don't think that there are adequate law or rules regarding mental illness. In conclusion, care givers experience stigma such as concealment, negative experience, emotional stigma as well as work related stigma which affects the health and recovery of mentally ill persons. Compliance to medicine was poor and relapse rate was high which also have impact on the life of caregiver.
\end{abstract}

\section{KEYWORDS}

Perception, stigma, caregivers, mentally ill

\section{CORRESPONDING AUTHOR}

Ms. Srijana Pandey

Department of Nursing,

Nepal Medical College Teaching Hospital

Attarkhel, Gokarneshwor-8, Kathmandu, Nepal

Email: srijanapandey2036@gmail.com

ORCID ID: 0000-0002-9044-5104 


\section{INTRODUCTION}

Stigma takes the form of stereotyping, distrust, fear, or avoidance and can negatively impact pursuit of treatment, employment and income, selfworth, and families. ${ }^{1}$

Families of persons with mental illness face a range of practical and emotional stresses. Studies suggest that the burden could come from the stigmatizing attitudes. Stigma surrounding mental illness is so strong, that it places a wall of silence around this issue. ${ }^{2}$

Increasing, health and socio-economic burden of mental illnesses and disorders have become a major concern in both developed and developing countries. Globally, it is estimated that more than 450 million people suffer from mental or behavioural disorders and one in four families has at least one member with a mental disorder (WHO, 2003). ${ }^{3}$

Persons with mental illness frequently encounter public stigma and may suffer from self-stigma. Stigma is of central importance to persons with mental illness, both to how they experience their illness and its consequences and whether they use available health services. Well-designed antistigma initiatives will help to diminish the impact of mental illness stigma. ${ }^{4}$

Self-stigma or internalized stigma is the process in which people with mental health problems turn the stereotypes about mental illness adopted by the public, towards themselves. They assume they will be rejected socially and so believe they are not valued (Livingston and Boyd, 2010). ${ }^{5}$

Family members were more likely to conceal the mental illness if they did not live with their ill relative, if the relative was female, and if the relative had less severe positive symptoms. Family members with more education and whose relative had experienced an episode of illness within the past 6 months reported greater avoidance by others. ${ }^{6}$

Mental illness was perceived as treatable; $12 \%$ preferred treatment from Tantric/Ojha. Community showed negative attitude for stereotyping, restrictiveness, and pessimistic prediction. $^{7}$

Anti-stigma programs are encouraged to create alliances with university researchers in order to critically evaluate their activities and build better, evidence informed practices. ${ }^{8}$

According to Link, self-stigma begins when people develop a lay theory about mental illness from childhood conceptualizations that reflect cultural images of mental illness. self-stigma begins with stereotype agreement: endorsing the same stereotypes perceived to be common in the public. For example, "I agree with the public; all people with mental illness are morally weak. ${ }^{9}$

Thus, it seems imperative for health professionals to do intervention regarding health awareness for general population to reduce stigma and promote mental health in the community. Hence, this study was designed to assess stigmatization belief of care givers in which this research can be helpful to administration, researcher, caregiver and general population.

\section{MATERIALS AND METHODS}

A descriptive study was conducted among 50 caregivers of mental illness patient with purposive sampling technique at Nepal Medical College Teaching Hospital, Kathmandu, Nepal from Oct 2018- Nov 2018. All the study participants were explained about the study objectives those who gave informed written consent and interviewed using socio-demographic performa and selfstigma of mental illness scale (SSMIS). ${ }^{9,16,20}$ It is an exploratory tool that covers stigma in areas of work (work related stigma=WR), family relationship (Emotional reaction=ER), social relationship and advocacy (negative experience=NE) and medical treatment(concealment $=\mathrm{C}$ ). Data was analyzed manually, edited, coded and entered in SPSS software version 16.Statistical analysis was performed using descriptive statistics. Inclusion criteria: Caregivers of persons with mental illness aged between 18 - 60 years who were living with the patient since the past 2 years. Exclusion criteria: Caregivers who had any major physical / psychiatric illness were excluded from the study. Ethical considerations: The study was approved by the research and ethical subcommittee of Nepal Medical College and Teaching Hospital. Informed written consent was taken.

\section{RESULTS}

The results shows that the most of the care givers were aged from 18-30 years and male and female respondents were equal. About half of them (52\%) were from rural areas. Most of the family type (88\%) were nuclear family. No history of mental illness in family were 58\%. Care givers reported that compliance to medication was poor among the patients (Table 2). About one-third caregivers (34\%) were father and mother and the least (18\%) were son and daughter (Table 3). Affected family member (70\%) had 1year and more duration of illness and least (12\%) was less than 6 months (Table 4). Preferred treatment was hospital for most $(78 \%)$ of the caregivers (Table 5). 
Table 1: Socio-Demographic status

\section{Characteristics}

Age group(years)

Gender

Education

Domicile

Family type

Family history

\section{Category}

18-30yrs

31-40yrs

41-50yrs

51-60yrs

Male

Female

illiterate

Can read and write

Higher secondary

Rural

Urban

Nuclear

Joint

yes

No

\section{Respondents}

$\begin{array}{cc}\text { Number } & \text { Percentage (\%) } \\ 24 & 48.0 \\ 7 & 14.0 \\ 8 & 16.0 \\ 11 & 22.0 \\ 25 & 50 \\ 25 & 50 \\ 12 & 24 \\ 24 & 48 \\ 14 & 28 \\ 26 & 52 \\ 24 & 48 \\ 44 & 88 \\ 6 & 12 \\ 21 & 42 \\ 29 & 58\end{array}$

\begin{tabular}{|lcc|}
\hline \multicolumn{3}{|c|}{ Table 2: Compliance to medication } \\
\hline Compliance to & Frequency & $\%$ \\
medication & Good & 18 \\
& Poor & 82 \\
\hline
\end{tabular}

Compliance to medication found to be $18 \%$ GOOD AND 82\% POOR (Table:2)

\begin{tabular}{|lcc|}
\hline \multicolumn{3}{|c|}{ Table 3: Relationship to the patient } \\
\hline Category & Frequency & $\mathbf{\%}$ \\
Father/mother/parents & 17 & 34 \\
Husband/wife/spouse & 12 & 24 \\
Son/daughter/adult & 9 & 18 \\
children & 12 & 24 \\
Brother/sister/siblings & & \\
\hline
\end{tabular}

\section{Table 4: Duration of illness}

\begin{tabular}{|lcc|} 
Category & Frequency & \% \\
Less than 6 months & 6 & 12 \\
Six months to one year & 9 & 18 \\
1 year and more & 35 & 70 \\
\hline
\end{tabular}

The study revealed that the most of caregivers (62\%) feel burdened financially and think that people with mental illness are dangerous (64\%). More than $2 / 3^{\text {rd }}$ care givers think that the mentally ill people are violent (70\%).

\begin{tabular}{|lcc|}
\hline \multicolumn{3}{|c|}{ Table 5: Preferred treatment } \\
\hline Category & Frequency & $\%$ \\
Traditional healers & 11 & 22 \\
Hospitals/psychiatric & 39 & 78 \\
\hline
\end{tabular}

Most of the caregivers think voluntary organizations are not doing adequate work in the field of mental health (54\%), and $72 \%$ feel that health organizations are giving less priority to mental illness as compared to other disorder.

Most of the caregivers, $(66 \%)$ think that their occupational life has been interfered by family's member illness, and 56\% don't think that there are adequate law/rules regarding mental illness.

The respondents by age were 18 -30 years (48\%) followed by 51-60 years (22\%),41-50years 16\%) and the least was of 31-40 years (16\%) (Table: 1). Male and female were equal ( $50 \%$ each); $24 \%$ Illeterate and remaining literate, $52 \%$ living in rural areas and $48 \%$ in urban and semi urban, $88 \%$ Nuclear and $12 \%$ joint family and $58 \%$ had no family history of mental problems (Table 1).

Table 3 reveals that the caregivers were parents (34\%) followed by Spouse and Siblings (24\% each) and adult children (18\%) (Table: 3 ).

The duration of illness was found to be more than a year of the $70 \%$ patients followed by 6 months to 1 year (18\%) and less than 6 months (12\%) (Table 4). 


\section{Table 6: Shows stigma scale. The following table is self explanatory.}

\section{S.No. Questionnaire}

$C=$ concealment $; \quad N E=$ negative experience $; \quad W R=$ Work related stigma; ER=Emotional stigma, negative experience reaction

1. I don,t like to tell that my family member has mental illness.(C)

2. Do you wait until you know a person well before you tell them about your family's mental illness.(C)

3. I don't like to tell that my family member is suffering from mental illness with health professionals also.(C)

4. I feel being discriminated in society due to my family member mental health problems. (NE)

5. I have been abused by other people in society by my family member mental health problem.(NE)

6. I feel burdened financially due to my family's mental health problems. (NE)

I feel like my neighbours and other closed member being

7. less supportive due to my family member mental health problems.(NE)

8. I feel like that media is publishing/broadcasting negative reports regarding mental illness?(NE)

9. I think that people with mental illness are dangerous. (NE)

10. I think that the mentally ill people are violent.(NE)

11. I feel that mentally ill people should be treated as criminals? (NE)

12. I experience to have sufficient true information about mental illness that have received. (NE)

13. I think voluntary organizations are doing adequate work in the field of mental health. (NE)

14. I feel health organizations are giving less priority to mental illness as compared to other disorder.(NE)

15. I think that my occupational life has been interfered by my family's member illness.(WR)

16. I have faced problems with house tenets due to mental illness of my family members. (WR)

17. I blame myself for my family members mental illness. (ER)

18. I think that there are adequate law/rules regarding mental illness.(ER)

I have been experiencing symptoms of mental illness as a

19. consequences on mental disorders in my family member. (ER)

20. I feel that my relationship has been strained due to my family's member mental illness. (ER)
Yes

Don't

know/

Can't say

No

$22(44 \%)$

$28(56 \%)$

$39(78 \%) \quad 2(4 \%)$

$9(18 \%)$

$18(36 \%)$

$32(64 \%)$

$13(26 \%)$

$1(2 \%)$

$36(72 \%)$

$6(12 \%)$

$44(88 \%)$

$31(62 \%) \quad 1(2 \%)$

$18(36 \%)$

$13(26 \%) \quad 3(6 \%)$

$34(68 \%)$

$2(4 \%)$

$1(2 \%)$

47(94\%)

$32(64 \%) \quad 3(6 \%)$

15(30\%)

35(70\%)

15(30\%)

$7(14 \%) \quad 2(4 \%)$

$41(82 \%)$

$11(22 \%) \quad 3(6 \%)$

$36(72 \%)$

$12(24 \%) \quad 11(22 \%)$

27(54\%)

$37(74 \%) \quad 4(8 \%)$

$9(18 \%)$

$33(66 \%)$

17(34\%)

$9(18 \%)$

$1(2 \%)$

$40(80 \%)$

$5(10 \%)$

$1(2 \%)$

$44(88 \%)$

10(20)

12(24\%)

$28(56 \%)$

$11(22 \%)$

$39(78 \%)$

$11(22 \%)$ 
The treatment for the mental problems has sought $78 \%$ in the hospital especially in psychiatric OPD and ward and $22 \%$ with traditional healers under self medication (Table 5).

\section{DISCUSSION}

Stigma of mental illness affects the health recovery, usage of health facilities, care and support of affected individual as well as caregivers' perception. This study revealed the caregivers stigma such as the negative reaction that mentally ill people are dangerous and violent, feeling financially burdened and do not have information about mental illness. They think that voluntary organizations are not doing adequate work in the field of mental health and feel that health organizations are giving less priority to mental illness as compared to other disorder.

Similar to this study carved out by Amjad. A, Lina S. A. Eltaib showed that lack of awareness about bio-medical concepts of mental illness and negative beliefs and attitudes about mentally ill persons and mental illness were prevalent among participants..$^{10}$ The study reported that $74 \%$ feel health organizations are giving less priority to mental illness as compared to other disorder of participants. ${ }^{10,11}$

This present study shows that financial and emotional implication to the family affected due to the stigma of families contains stereotypes of blame, shame, social rejection and a combination of other related attitudes towards the family is similar to the study finding done by Benti $\mathrm{M}$, Ebrahim J, Awoke T, Yohannis Z, Bedaso A. ${ }^{11}$

Similar to this study finding done by Sadik S, Bradley M, Hasoon S Al and Jenkins R. that understanding of the nature of mental illness, its implications for social participation and management remains negative in general. ${ }^{12}$

However, the findings with this study and study done by Corrigan $\mathrm{P}$ explores that many people who would benefit from mental health services opt not to pursue them or fail to fully participate once they have begun. One of the reasons for this disconnect is stigma; namely, to avoid the label of mental illness and the harm it brings, people decide not to seek or fully participate in care. ${ }^{13}$

The study showed that stigma of emotional reaction as no adequate rules and regulation regarding mental illness. Similarly, The result of both, people with mental illness are robbed of the opportunities that define a quality life: good jobs, safe housing, satisfactory health care, and affiliation with a diverse group of people. ${ }^{14}$
The findings at work related stigma was as work life interfered with family's member illness are in corroboration with previous studies by BenZeev D, Young MA, Corrigan PW in DSM-V and the stigma of mental illness states that stigma associated with mental illness has been shown to have devastating effects on the lives of people with psychiatric disorders, their families, and those who care for them. ${ }^{15}$

Stigma defines people in terms of some distinguishing characteristic and devalues them as a consequence. ${ }^{16,17}$ Similar to this study, the present study shows the experience by care giver that they are danger and violent.

The study finding is similar to the study done by Adhikari $S$ that the Stigma experienced by relatives is pervasive and everlasting. It deeply affects emotional, social and occupational aspects of care giver also which leads to concealment of their patient's illness, which have long term detrimental situations and non-compliance of medications. ${ }^{18}$

This finding is contrary to findings from a study done by Yow TS. ${ }^{19}$ The study found that concealment was hide disease and don't like to say relatives mental illness was more than half of population.

This study finding recommendation is similar to the study done by the various interventions to deal with stigma have been classified as individual level interventions, community level interventions, and structural interventions, counseling and cognitive behavior therapy ${ }^{20}$ is similar to this study finding recommendation which aids in nursing practice is highly recommeded from this study. ${ }^{20}$

In conclusion, care givers experience stigma such as concealment, negative experience, emotional stigma as well as work related stigma which affects the health, recovery. Compliance to medicine was poor and relapse rate was high which also have impact on the life of caregiver.

\section{ACKNOWLEDEMENTS}

The author would like to acknowledge to all the participants and grateful to all who helped me directly and indirectly. 


\section{REFERENCES}

1. Domingo PS and Ann C S. Labid.Social Stigma, Stigma Management among Probationers and Parolees of Samar, Philippines. IJMAS 2016;3.www. ijmas.com

2. Y B Pravin, G M Jahanara, GSangeeta, SBhusanShashi. Comparative study of perception of stigma among caregivers of persons with Bipolar affective disorder and Schizophrenia. J Huma Soc Sci 2015; 20: 01-06.

3. Fiasorgbor A D, Aniah A S. Perceptions and Beliefs about Mental Illness (Schizophrenia) among Adults in Zaare Community. 2015[cited 2016 july 25]; 5: 150-158. Available from:www.iiste.org.

4. Rüsch N, Angermeyer MC, Corrigan PW. The stigma of mental illness: concepts, forms, and consequences. Psychiatr Prax 2005; 32 : 221-32.

5. Siobhan P. How does stigma affect people with mental illness? J Nurs Times 2012; 108: 12-14.

6. Phelan C, BrometJ E, and Q Bruce. Psychiatric Illness and Family Stigma. [cited 2016 july 25];

7. Salve H1, Goswami K, Sagar R, Nongkynrih B, Sreenivas V. Perception and Attitude towards Mental Illness in an Urban Community. Indian J Psychol Med 2013; 35: 154-8.

8. H Stuart. Reducing the stigma of mental illness. Glob Ment Health 2016; 3:e 17. Retrieved from ncbi. nlm.nih/pmc/articles.

9. Corrigan PW, Watson AC, Barr L. The self-stigma of mental illness: Implications for self-esteem and self-efficacy. J Soc Cl Psychol 2006; 25: 875-84.

10. amjad. A, lina s.A. Eltaib. Public attitude and perception of mental illness in saudi Arabia. Amer J Res Communication 2018; 6: 116-35.
11. Benti M, Ebrahim J, Awoke T, Yohannis Z, Bedaso A. Community Perception towards Mental Illness among Residents of Gimbi Town, Western Ethiopia. 2016; Retrived from: www.hindawi.com.

12. Sadik S, Bradley M, Hasoon S Al and Jenkins R. Public perception of mental health. Int'l J Ment Health Syst 2010; 4: 26.

13. Corrigan P. How stigma interferes with mental health care. Am Psychol. 2004; 59: 614-625.Available from: http://www.studymode.com/essays/howstigma-interferes-with mental health care

14. Corrigan PW, Watson AC. Understanding the impact of stigma on people with mental illness. $J$ world Psych 2002; 1: 16-20.

15. Ben-Zeev D, Young MA, Corrigan PW. DSM-V and the stigma of mental illness. J Ment Health 2010; 19: 318-27.

16. Dinos S1, Stevens S, Serfaty M, Weich S, King M.Stigma: the feelings and experiences of 46 people with mental illness. Br J Psychiatry 2004; 184: $176-81$.

17. Corrigan Pw. and Shah b binoy. Understanding and Addressing the Stigma Experienced by People with First Episode Psychosis.

18. Adhikari S R. Stigma in Mental Illness: Relative's Perspective. J Psychiatr Assoc Nepal 2014; 3: 37-42.

19. Yow T S. Perceived stigma and coping strategies among Asians with schizophrenia: The Singapore case. National University of Singapore.

20. Aakansha Singh, Surendra K Mattoo, Sandeep Grover. Stigma associated with mental illness: Conceptual issues and focus on stigma perceived by the patients with schizophrenia and their caregivers. Indian J Soc Psychiatr 2016; 32: 134-42. 